\title{
Dental prosthetic status and prosthetic needs of geriatric patients attending the College of Dentistry, Al Jouf University, Kingdom of Saudi Arabia
}

Bader K. AlZarea ${ }^{1}$

Correspondence: Dr. Bader K. AlZarea

Email: bkazarea@ju.edu.sa
'Department of Prosthodontics, College of Dentistry, Aljouf University, Sakakah, Saudi Arabia

\section{ABSTRACT}

Objective: To evaluate the dental prosthetic status and prosthetic needs of geriatric patients attending the College of Dentistry, Al Jouf University, Kingdom of Saudi Arabia. Materials and Methods: Patients aged 60 years and above were included in this study. The World Health Organization oral health assessment pro forma was employed to record the data pertaining to the prosthetic status and prosthetic treatment needs of participants. Data obtained were analyzed using the Statistical Package for the Social Sciences (SPSS, Chicago, IL, USA) Version 20.0. Differences in proportions were compared using the Chi-square test. Results: Out of 286 edentulous patients, $69.06 \%$ needed some form of prosthetic treatment, $73.77 \%$ did not have any prosthesis in upper arch, and $80.06 \%$ did not have any prosthesis in lower arch. Out of 162 males, 32.09\% and $26.54 \%$ had prosthesis in upper and lower arch, respectively. Among 124 females, $18.54 \%$ and $19.35 \%$ had prosthesis in upper and lower arch, respectively. In males, the need for any type of prosthesis in upper and lower arch was $68.51 \%$ and $75.92 \%$, respectively. In females, the need for prosthesis in upper and lower arch was $57.25 \%$ and $72.58 \%$, respectively. The need for multiunit prosthesis was more in both arches in both genders. The need for complete denture and combination of single- or multiunit prosthesis was more among the males as compared to females in maxilla and vice versa for mandible. Conclusion: The observations of this study propose that the greater part of the prosthetic needs were insufficient among the geriatric people.

Key words: Dental prosthetic status, edentulism, geriatric patients, prosthetic needs

\section{INTRODUCTION}

Aging is ubiquitous, imminent, and indelible biological process, which influence one and all. ${ }^{[1]}$ An increased number of the geriatric people suggests an imperative demographic change throughout the world. As recommended by the World Health Organization (WHO), a populace maturing over 60 years of age ought to be considered to be an elderly population, and furthermore, the elderly constitute around $3.5 \%$ of the total population of Saudi Arabia. ${ }^{[2]}$ In recent time, progresses in therapeutic sciences and enhanced social conditions have

\begin{tabular}{|l|l|}
\hline \multicolumn{2}{|c|}{ Access this article online } \\
\hline Quick Response Code: \\
\hline
\end{tabular}

fundamentally expanded average life expectancy of the people around the world. This may posture colossal difficulties to those included in providing the care that is needed for geriatric population. ${ }^{[3]}$ It turns into the mission of the health-care providers to work not only to expand the life expectancy but also rather additionally and maybe more vitally to make later years of life more beneficial and pleasant. ${ }^{[4]}$

Optimal oral health is an indispensable component for the healthful living, and oral well-being can

This is an open access article distributed under the terms of the Creative Commons Attribution-NonCommercial-ShareAlike 3.0 License, which allows others to remix, tweak, and build upon the work non-commercially, as long as the author is credited and the new creations are licensed under the identical terms.

For reprints contact: reprints@medknow.com

How to cite this article: AlZarea BK. Dental prosthetic status and prosthetic needs of geriatric patients attending the College of Dentistry, Al Jouf University, Kingdom of Saudi Arabia. Eur J Dent 2017;11:526-30. DOI: 10.4103/ejd.ejd_69_17 
be regarded as an index of general well-being and personal satisfaction in elderly people. Disorders of the oral cavity are radical and amassing and can turn into unpredictable after sometime. ${ }^{[5,6]}$ Among the numerous maladies and ailments that the aged individuals experience the ill effects of, disorders related to the oral cavity possess a critical role. Enhanced oral health will permit aged individuals to ameliorate their self-assurance, have social contacts, and reestablish the capacity to work. Loss of tooth is turning into a vital general health problem among a greater proportion of extent of geriatric persons. ${ }^{[5]}$ Edentulism impacts dietary habit, particularly in terms of restricted masticatory functioning, consequently leading to weight reduction and pertinent systemic illnesses among the aged individuals. Aside from this, tooth loss might be sincerely discouraging for the greater part of the elderly individuals. It can likewise prompt to abstaining of day-to-day activities and may brunt personal satisfaction. ${ }^{[7,8]}$

The elderly individuals may confront the most noteworthy number of barriers to oral health administrations regarding financial elements, absence of treatment resources, and coinciding various chronic and psychological illnesses. The evaluation of therapeutic requirements among elderly people is a critical prerequisite in oral health-care planning, and to accomplish this, it is fundamental to enact specific objectives ${ }^{[9]}$ One of the initial phases in planning dental administrations is subsequently, the compilation of data on the prevalence of oral disorders in a given populace, and accordingly, we should know about the prosthetic status and a prosthetic need of this populace. With these data, it is conceivable to survey future treatment needs and requests for services. ${ }^{[10]}$

Data on prosthetic status and prosthetic need among the geriatric individuals are very minimal, and to the best our knowledge, no such study was carried out in Kingdom of Saudi Arabia. Therefore, this research was carried out with an aim to exploring and assessing the prosthetic status and prosthetic needs of the geriatric population.

\section{MATERIALS AND METHODS}

This cross-sectional survey was carried out to determine the prosthetic status and prosthetic need among the geriatric patients attending the College of Dentistry, Aljouf University University, Saudi Arabia, from October 2014 to March 2016. Approval for the study was obtained from the Institutional
Ethical Committee. Patients had been made aware of the nature and aim of the investigation and have been included in the study after they signed informed consent. All patients aged 60 years and above constituted the study sample. The WHO oral health assessment pro forma ${ }^{[11]}$ was employed to record the data pertaining to the prosthetic status and prosthetic treatment needs of the participants. Data were analyzed using the Statistical Package for the Social Sciences (SPSS; IBM, USA) Version 20 software. Differences in proportions were compared using the Chi-square test.

\section{RESULTS}

Sociodemographic characteristics of study population are described in Table 1. It indicates that, out of 286 patients, a maximum of $56.64 \%$ were males, $33.91 \%$ of patients belonged to $<60$ years of age group, $45.80 \%$ of patients belonged to upper middle SES, and $40.55 \%$ of patients had secondary-school education followed by others.

Table 2 represents the distribution of study subjects according to gender and the prosthetic status with regard to upper arch. Out of 286 patients, a maximum of $81.45 \%$ femalesand $67.90 \%$ males were without any prosthesis in upper arch as compared to $8.64 \%$ of males and $4.03 \%$ of females having bridge, $5.64 \%$ of females and $6.79 \%$ of males having both bridge

Table 1: Sociodemographic characteristics of study
population


and partial denture, and $7.40 \%$ of males and $4.03 \%$ of females having removable denture followed by those having $>1$ bridge in the upper arch. The differences between males and females with prosthesis status were found to statistically nonsignificant (Chi-square $=8.7163, P=0.1213$ ).

Table 3 shows the distribution of study subjects according to gender and the prosthetic status with regard to lower arch. Among 286 patients, a maximum of $88.7 \%$ females and $73.4 \%$ males had no prosthesis in lower arch as compared to $8.02 \%$ of males and $3.22 \%$ of females having bridge, $0.80 \%$ of females and $3.70 \%$ of males having both bridge and partial denture, and $6.17 \%$ of males and $4.03 \%$ of females having removable denture followed by those having $>1$ bridge in lower arch. The differences between males and females with prosthesis status were found to statistically significant (Chi-square $=11.1712, P=0.0483$ ).

Distribution of study subjects according to gender and the prosthetic need with regard to upper arch are mentioned in Table 4 . Out of 286 patients, a maximum of $31.48 \%$ males and $42.74 \%$ females not required any prosthesis in upper arch as compared to $4.93 \%$ of males and $8.06 \%$ of females needing single-unit prosthesis in upper arch, $29.01 \%$ of males and $25.80 \%$ of females needing multiunit prosthesis in upper arch, and $27.77 \%$ of males and $17.74 \%$ females needing fullmouth prosthesis in upper arch followed by $6.79 \%$ of males and $5.64 \%$ of females needing combination of single- or multiunit prosthesis in upper arch. The differences between males and females with prosthetic needs were found to be statistically nonsignificant (Chi-square $=6.9672, P=0.1385$ ).

Table 5 shows the distribution of study subjects according to gender and the prosthetic need with regard to lower arch. Among 286 patients, in which $24.07 \%$ of males and $27.41 \%$ of females required no prosthesis in lower arch as compared to $5.55 \%$ of males and $10.48 \%$ of females having need for single-unit prosthesis, $35.18 \%$ of males and $21.77 \%$ of females having need for multiunit prosthesis, and $26.54 \%$ of males and $28.22 \%$ of females having need for full mouth prosthesis followed by $8.64 \%$ of males and $12.09 \%$ of females who needed combination of single- or multiunit prosthesis in lower arch. The differences between males and females with prosthesis needs were found to statistically nonsignifi cant (Chi-square $=7.7265, P=0.1024)$.

\begin{tabular}{|c|c|c|c|}
\hline Prosthetic status & Male (\%) & Female (\%) & Total (\%) \\
\hline No prosthesis & $110(67.90)$ & $101(81.45)$ & $211(73.77)$ \\
\hline Bridge & $14(8.64)$ & $5(4.03)$ & $19(6.64)$ \\
\hline More than one bridge & $7(4.32)$ & $1(0.80)$ & $8(2.79)$ \\
\hline Partial denture & $8(4.93)$ & $5(4.03)$ & $13(4.54)$ \\
\hline $\begin{array}{l}\text { Both bridge and } \\
\text { partial denture }\end{array}$ & $11(6.79)$ & $7(5.64)$ & $18(6.29)$ \\
\hline Full removable denture & $12(7.40)$ & $5(4.03)$ & $17(5.94)$ \\
\hline Not recorded & 0 & 0 & 0 \\
\hline Total & $162(100)$ & $124(100)$ & $286(100)$ \\
\hline$\chi^{2}, P$ & & $8.7163,0.1213$ & \\
\hline
\end{tabular}

\begin{tabular}{|c|c|c|c|}
\hline Prosthetic status & Male (\%) & Female (\%) & Total (\%) \\
\hline No prosthesis & $119(73.4)$ & $110(88.7)$ & $229(80.06)$ \\
\hline Bridge & $13(8.02)$ & $4(3.22)$ & $17(5.94)$ \\
\hline More than one bridge & $5(3.08)$ & $1(0.8)$ & $6(2.09)$ \\
\hline Partial denture & $9(5.55)$ & $3(2.41)$ & $12(4.19)$ \\
\hline $\begin{array}{l}\text { Both bridge and } \\
\text { partial denture }\end{array}$ & $6(3.70)$ & $1(0.8)$ & $7(2.44)$ \\
\hline Full removable denture & $10(6.17)$ & $5(4.03)$ & $15(5.24)$ \\
\hline Not recorded & 0 & 0 & 0 \\
\hline Total & $162(100)$ & $124(100)$ & $286(100)$ \\
\hline$\chi^{2}, P$ & & $11.1712,0.0483^{*}$ & \\
\hline
\end{tabular}

\begin{tabular}{|c|c|c|c|}
\hline Prosthetic needs & Male (\%) & Female (\%) & Total (\%) \\
\hline No prosthesis required & 51 (31.48) & $53(42.74)$ & $104(36.36)$ \\
\hline $\begin{array}{l}\text { Need for single-unit } \\
\text { prosthesis }\end{array}$ & $8(4.93)$ & $10(8.06)$ & $18(6.29)$ \\
\hline Need for multiunit prosthesis & $47(29.01)$ & $32(25.80)$ & $79(27.62)$ \\
\hline $\begin{array}{l}\text { Need for combination } \\
\text { of single- or multiunit } \\
\text { prosthesis }\end{array}$ & $11(6.79)$ & $7(5.64)$ & $18(6.29)$ \\
\hline $\begin{array}{l}\text { Need for full mouth } \\
\text { prosthesis (replacement } \\
\text { of all teeth) }\end{array}$ & $45(27.77)$ & $22(17.74)$ & $67(23.42)$ \\
\hline Not recorded & 0 & 0 & 0 \\
\hline Total & $162(100)$ & $124(100)$ & $286(100)$ \\
\hline$\chi^{2}, P$ & & $6.9672,0.1385$ & \\
\hline
\end{tabular}

\section{DISCUSSION}

This was the first cross-sectional study carried out to evaluate the prosthetic status and prosthetic needs of the geriatric patients attending the College of Dentistry, Al Jouf University, Kingdom of Saudi Arabia.

The population aged 60 years and above residing were selected, and a total of 286 patients were included 


\begin{tabular}{|c|c|c|c|}
\hline Prosthetic needs & Male (\%) & Female (\%) & Total (\%) \\
\hline No prosthesis required & $39(24.07)$ & $34(27.41)$ & $73(25.52)$ \\
\hline $\begin{array}{l}\text { Need for single-unit } \\
\text { prosthesis }\end{array}$ & $9(5.55)$ & $13(10.48)$ & $22(7.69)$ \\
\hline Need for multiunit prosthesis & $57(35.18)$ & $27(21.77)$ & $84(29.37)$ \\
\hline $\begin{array}{l}\text { Need for combination of } \\
\text { single- or multiunit prosthesis }\end{array}$ & $14(8.64)$ & 15 (12.09) & $29(10.13)$ \\
\hline $\begin{array}{l}\text { Need for full mouth } \\
\text { prosthesis (replacement } \\
\text { of all teeth) }\end{array}$ & $43(26.54)$ & $35(28.22)$ & $78(27.27)$ \\
\hline Not recorded & 0 & 0 & 0 \\
\hline Total & $162(100)$ & $124(100)$ & $286(100)$ \\
\hline$\chi^{2}, P$ & \multicolumn{3}{|c|}{$7.7265,0.1024$} \\
\hline
\end{tabular}

in this study. All the examinations were carried out under standardized conditions, and prosthetic status and prosthetic needs of the participants were recorded.

Out of 286 edentulous patients, $69.06 \%$ needed some form of prosthetic treatment, and an incidence varying from $76 \%$ to $88 \%$ was reported in various studies. This low extent of individuals with prostheses regardless of the need might be ascribed to one of these few reasons such as absence of information, paucity of enthusiasm for esthetics, monetary limitations, and the lack of availability of dental services.

Out of 286 edentulous patients, $73.77 \%$ did not have any prosthesis in upper arch and $80.06 \%$ did not have any prosthesis in lower arch; this rate was comparably high in comparison to institutionalized samples in study of Deogade et al. ${ }^{[12]}$ and was lower than that of Shenoy and Hegde. ${ }^{[13]}$ This finding was also low when compared with observation of Shah et al. and Ettinger et al., where they included patients with wider age group. ${ }^{[14]}$

Out of 162 males, $32.09 \%$ and $26.54 \%$ had prosthesis in upper and lower arch, respectively. Among 124 females, $18.54 \%$ and $19.35 \%$ had prosthesis in upper and lower arch, respectively. Females had comparatively less prosthesis in both arches than males. This was in accordance with the findings of Shah et al., ${ }^{[5]}$ Deogade et al., ${ }^{[12]}$ and Shenoy and Hegde. ${ }^{[13]}$ Comparable findings have been recorded in studies conducted in various parts of the world. ${ }^{[15-18]}$ The rationale behind female patients presenting fewer prostheses than their counterparts was due to their dependency, a lower level of education, and lack of employment. These conclusions are in accordance with the study conducted by Shenoy and Hegde. ${ }^{[13]}$
The differences between males and females with prosthesis need were found to be statistically not significant in relation to both upper and lower arches; this observation was similar with that of Shenoy and Hegde, ${ }^{[13]}$ whereas Shah et al..$^{[5]}$ found that males had higher prosthetic need as compared to females.

In males, the need for any type of prosthesis in upper and lower arch was $68.51 \%$ and $75.92 \%$, respectively. It was higher than survey held by Montal et al. in France ${ }^{[19]}$ and Shah et al ${ }^{[5]}$ and Shigali et al. in India. ${ }^{[20]}$

In female patients, the need for prosthesis in upper and lower arch was $57.25 \%$ and $72.58 \%$, respectively, which was more than that of Shah et al. ${ }^{[5]}$ and Shenoy and Hegde ${ }^{[13]}$ and less than that of Deogade et al. ${ }^{[12]}$

The need for multiunit prosthesis was more in both upper and lower arches in both genders. This observation was similar to that of Shah et al., ${ }^{[5]}$ Deogade et al., ${ }^{[12]}$ and Shenoy and Hegde. ${ }^{[13]}$

In the present study, the need for complete denture and combination of single- or multiunit prosthesis was more among the males as compared to females in maxilla and vice versa for mandible. Deogade et al. ${ }^{[2]]}$ and Slade et al..$^{[18]}$ observed that the need for full prostheses was more than the need for multiunit prostheses or the need for a combination of one and multiunit prosthesis in females. Shenoy and Hegde ${ }^{[13]}$ observed that the need for full prostheses in upper and lower arches was more in comparison to the need for partial dentures, and the need was slightly more in males than in females. Shah et al.$^{[5]}$ noted that a need for complete denture was more among the males as compared to females, and they proposed that these might be due to tobacco-related habits which are common in males. Hongal et al. noted that the need for single-unit prosthesis was highest among females, and males were required more multiunit prosthesis. ${ }^{[21]}$

\section{CONCLUSION}

The results of this study propose that the greater part of the prosthetic needs were insufficient among the geriatric people. These outcomes may serve as a beneficial guideline for the future assessment of prosthetic status and prosthetic need among the geriatric people. The observations from this study may accord to the evolution of an oral health-care concord for the elderly individuals to enhance their dental perception and revamp their oral health. 


\section{Financial support and sponsorship}

Nil.

\section{Conflicts of interest}

There are no conflicts of interest.

\section{REFERENCES}

1. Bulterijs S, Hull RS, Björk VC, Roy AG. It is time to classify biological aging as a disease. Front Genet 2015;6:205.

2. Al-Modeer MA, Hassanien NS, Jabloun CM. Profile of morbidity among elderly at home health care service in Southern Saudi Arabia. J Family Community Med 2013;20:53-7.

3. Singh A, Purohit BM. Addressing geriatric oral health concerns through national oral health policy in India. Int J Health Policy Manag 2015;4:39-42.

4. Bunker JP. The role of medical care in contributing to health improvements within societies. Int J Epidemiol 2001;30:1260-3.

5. Shah VR, Shah DN, Parmar CH. Prosthetic status and prosthetic need among the patients attending various dental institutes of Ahmedabad and Gandhinagar District, Gujarat. J Indian Prosthodont Soc 2012;12:161-7.

6. Peeran SA, Al Sanabani F, Al-Makramani BM, Elamin EI. Dental prosthetic status and treatment needs of adult population in Jizan, Saudi Arabia: A survey report. Eur J Dent 2016;10:459-63.

7. Petersen PE. The World Oral Health Report 2003: Continuous improvement of oral health in the $21^{\text {st }}$ century - The approach of the WHO Global Oral Health Programme. Community Dent Oral Epidemiol 2003;31 Suppl 1:3-23.

8. Pekiner F, Gumru B, Borahan MO, Aytugar E. Evaluation of demands and needs for dental care in a sample of the Turkish population. Eur J Dent 2010;4:143-9.

9. Mack F, Mundt T, Budtz-Jørgensen E, Mojon P, Schwahn C, Bernhardt $\mathrm{O}$, et al. Prosthodontic status among old adults in Pomerania, related to income, education level, and general health (results of the
Study of Health in Pomerania, SHIP). Int J Prosthodont 2003;16:313-8.

10. Zeid WM, Mohamed MH, Mahdy NH, El-Tabakh SM. Categorical analysis of factors affecting needs and demands for removable dentures among Alexandria dental Research Center clientele. J Egypt Public Health Assoc 1999;74:371-405.

11. World Health Organization. Oral Health Surveys Basic Methods. $4^{\text {th }}$ ed. Geneva: World Health Organization; 1997.

12. Deogade SC, Vinay S, Naidu S. Dental prosthetic status and prosthetic needs of institutionalised elderly population in oldage homes of Jabalpur city, Madhya Pradesh, India. J Indian Prosthodont Soc 2013;13:587-92.

13. Shenoy RP, Hegde V. Dental prosthetic status and prosthetic need of the institutionalized elderly living in geriatric homes in Mangalore: A pilot study. ISRN Dent 2011;2011:987126.

14. Ettinger RL, Beck JD, Jakobsen J. Removable prosthodontic treatment needs: A survey. J Prosthet Dent 1984;51:419-27.

15. Soh G, Chong YH, Ong G. Dental prosthetic status and needs of an elderly population living in long-term care facilities in Singapore. J Community Health 1992;17:175-81.

16. Shah N, Parkash H, Sunderam KR. Edentulousness, denture wear and denture needs of Indian elderly - A community-based study. J Oral Rehabil 2004;31:467-76.

17. Palmqvist S. Treatment needed and received in an elderly Swedish county population. Gerodontics 1988;4:272-6.

18. Slade GD, Spencer AJ, Gorkic E, Andrews G. Oral health status and treatment needs of non-institutionalized persons aged 60+in Adelaide, South Australia. Aust Dent J 1993;38:373-80.

19. Montal S, Tramini P, Triay JA, Valcarcel J. Oral hygiene and the need for treatment of the dependent institutionalised elderly. Gerodontology 2006;23:67-72.

20. Shigli K, Hebbal M, Angadi GS. Attitudes towards replacement of teeth among patients at the institute of dental sciences, Belgaum, India. J Dent Educ 2007;71:1467-75.

21. Hongal S, Torwane N, Chandrashekhar B, Saxena V, Chavan K. An evaluation of dental prosthetic status and prosthetic needs among eunuchs (Trans genders) residing in Bhopal City, Madhya Pradesh, India: A cross-sectional study. Ann Med Health Sci Res 2014;4:943-8. 